\title{
Correction to: Development of Nanocrystal Ziprasidone Orally Disintegrating Tablets: Optimization by Using Design of Experiment and In Vitro Evaluation
}

\author{
Emine Tashan, ${ }^{1,2}$ Alptug Karakucuk, ${ }^{1}$ and Nevin Celebi ${ }^{1,3}$
}

Correction to: AAPS PharmSciTech 21, 115 (2020)

https://doi.org/10.1208/s12249-020-01653-9

Several typos occurred during the production process and captions were misplaced. The corrected captions for Picture 1, Fig. 6, Fig. 7, Fig. 8 and Fig. 9 are below.

The online version of the original article can be found at https:// doi.org/10.1208/s12249-020-01653-9

\footnotetext{
${ }^{1}$ Department of Pharmaceutical Technology, Faculty of Pharmacy Gazi University, Ankara, Turkey.

${ }^{2}$ Zoleant Pharmaceuticals International, Istanbul, Turkey.

${ }^{3}$ To whom correspondence should be addressed. (e-mail: ncelebi51@gmail.com)
} 


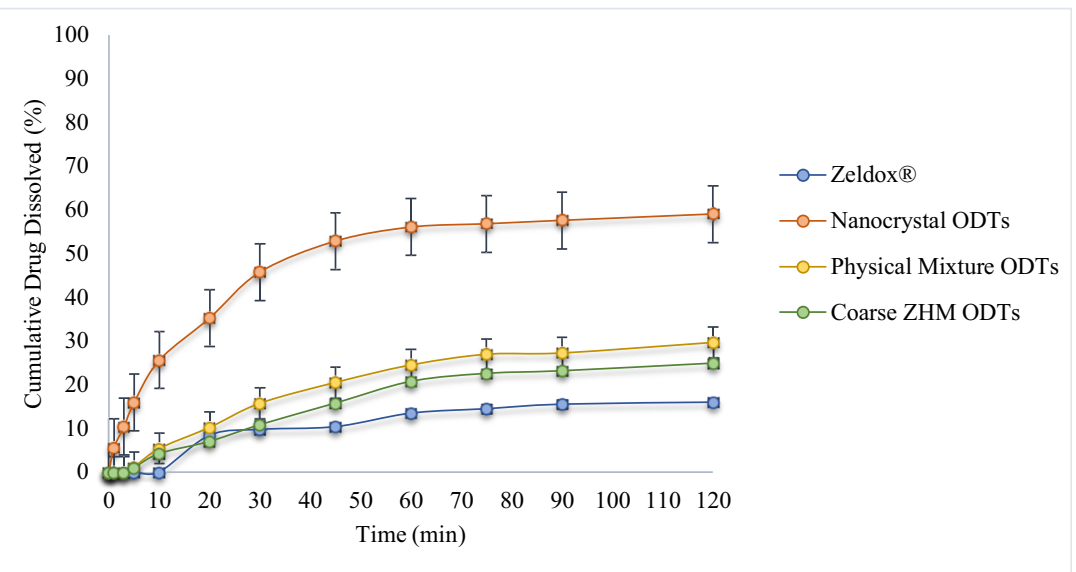

Fig. 6.. Dissolution profiles of ODTs in $\mathrm{pH} 7.4$ phosphate buffer

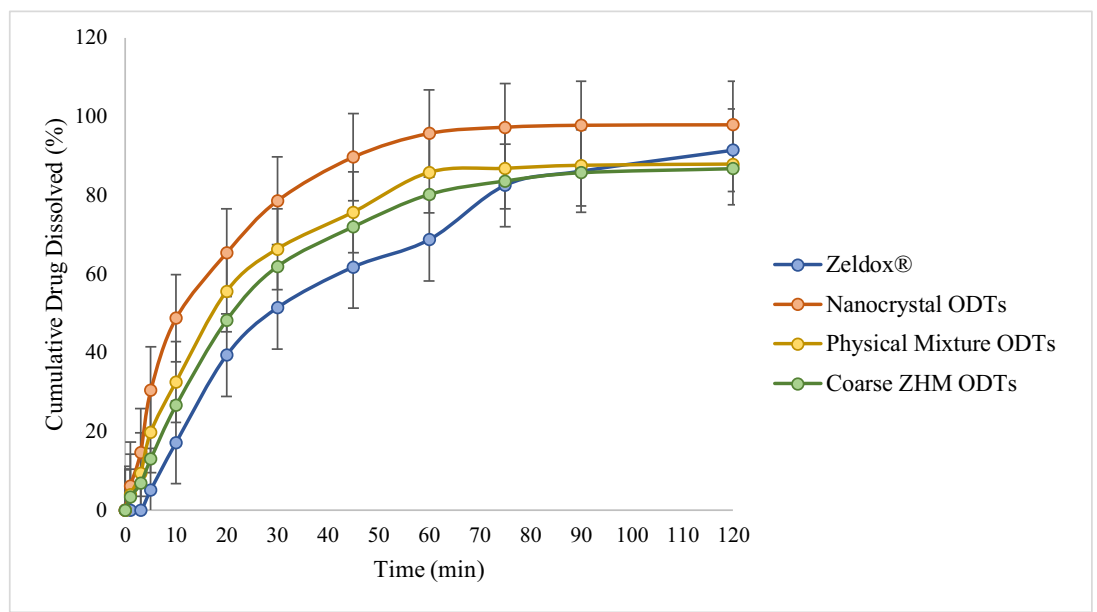

Fig. 7. Dissolution profiles of ODTs in $\mathrm{pH} 7.4$ phosphate buffer $+1 \%$ SLS

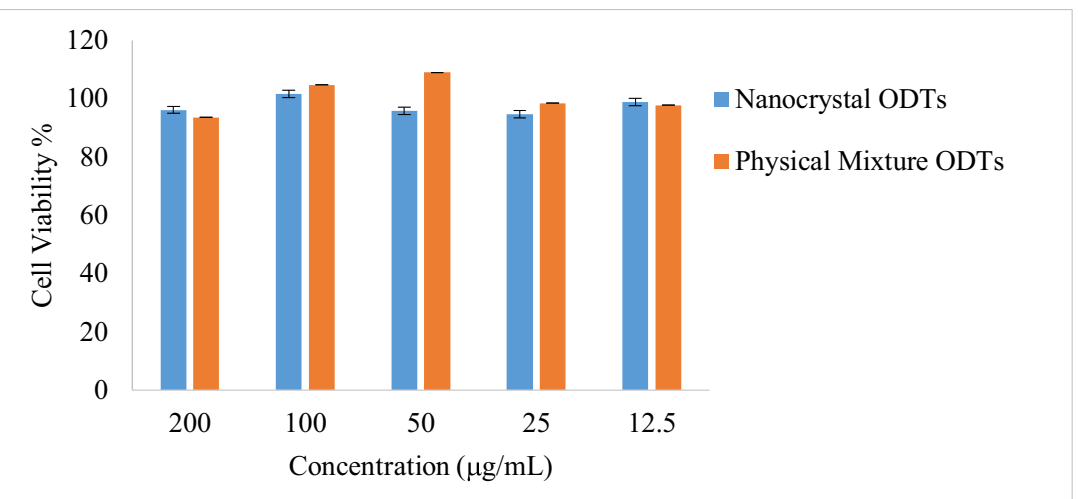

Fig. 8. Cell viabilities (\%) for the sample groups $(n=6)$ 


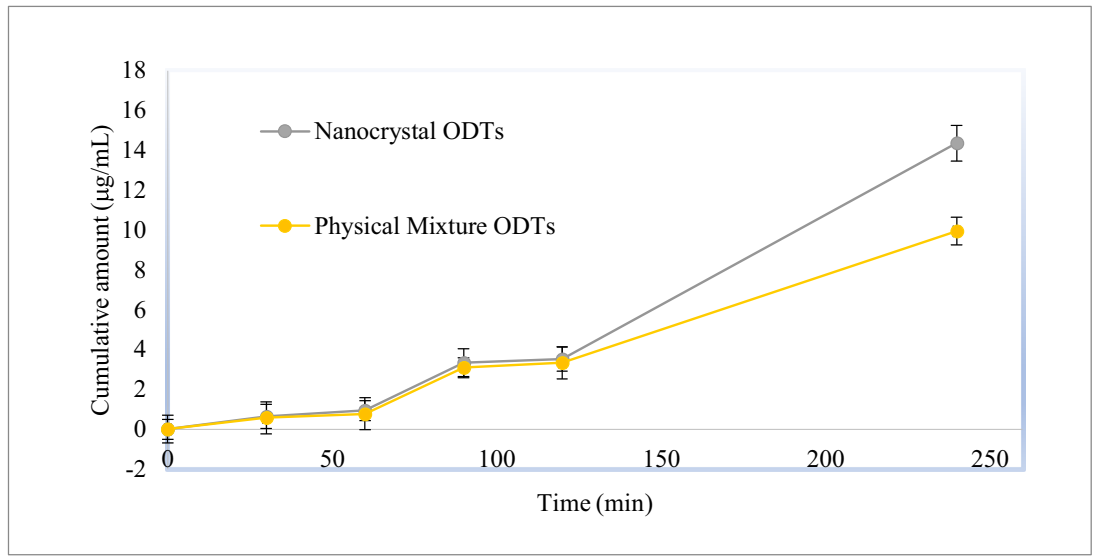

Fig. 9. Cumulative amount of ZHM in basolateral membrane

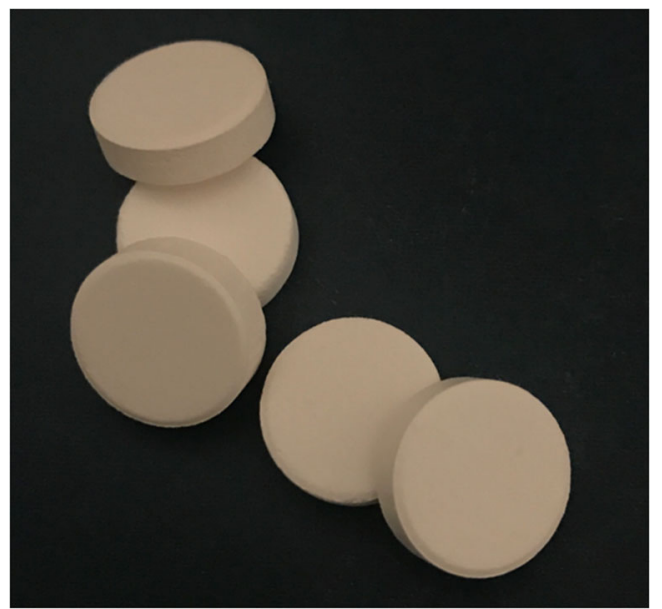

Picture. 1. Appearance of nanocrystal based ODTs 